\title{
REDUCTION OF INTERLEUKIN-1ß EXPRESSION IN RHEUMATOID ARTHRITIS BY LINEAR POLARIZED NEAR INFRARED LIGHT IRRADIATION
}

\author{
Noboru Kuboyama ${ }^{1}$, Lin Zhang ${ }^{2}$, Ying Li ${ }^{1}$, Masahiko Kanenari ${ }^{2}$, Rie Yoshimura ${ }^{2}$, \\ Shu-Guei Wang ${ }^{2}$, Hideo Kimura ${ }^{2}$ and Yoshimitsu Abiko ${ }^{2}$ \\ 1: Departments of Molecular Pharmacology \\ 2: Department of Biochemistry and Molecular Biology, Nihon University School \\ of Dentistry at Matsudo, Chiba, Japan
}

\begin{abstract}
Background: Rheumatoid arthritis (RA) is a systemic autoimmune disorder that involves inflammation and pain of joints. Low-level light therapy (LLLT) is being evaluated for treating RA. However, the molecular basis mechanism underlying the effectiveness of linear polarized near infrared light irradiation (LPIL) is unclear. It has been reported that interleukin $1 ß$ (IL-1ß) plays a key role in the progression of RA.

Aim: The objective of this study was to determine whether LPIL (Super Lizer ${ }^{\mathrm{TM}}$; SL) decrease gene expression and production IL-1ß in human RA synovial cells, MH7A, and RA joint tissue of collagen-induced-rheumatoid arthritis (CIA) rats.

Materials and Methods: IL-1ß challenged MH7A and CIA rat joints were irradiated with SL. Total RNA was isolated from MH7A, and gene expression profiles were analyzed using DNA microarray. The mRNA levels were confirmed by reverse transcription-polymerase chain reaction (RT-PCR) and real-time PCR. The production of IL-1ß in rat knee joints was analyzed by immunohistochemistry.

Results: DNA microarray analysis showed that IL- $1 \beta$ increased IL- $1 \beta$ gene expression in MH7A, and SL significantly reduced its IL-1ß mRNA level. The reduction of IL-1ß mRNA level by SL was successfully confirmed by reverse RT-PCR and real-time PCR. SL reduced the swelling of CIA rat knee joints, and the immunohistochemical study demonstrated that a strong IL-1ß staining in synovial membrane tissue of CIA rat joint, and the immuno-staining was significantly reduced by SL.

Conclusion: Since autocrine IL-1ß production has been identified to be an important proinflammatory cytokine in the pathogenesis of RA, the reduction of IL-1ß expression in RA synovial cells is one of mechanisms in reduction of the inflammation in RA by SL.
\end{abstract}

Key Words: Rheumatoid arthritis, Rat joint, IL-1B, gene expression

\section{Introduction}

Rheumatoid arthritis (RA) is a chronic inflammatory disease characterized by pain and inflammation, progressive joint destruction, significant disability, systemic manifestations and premature mortality. ${ }^{1)}$ This disease is characterized by the infiltration of leukocytes into

\section{Addressee for Correspondence:}

Yoshimitsu Abiko DDS, PhD

Department of Biochemistry and molecular Biology, Nihon

University School of Dentistry at Matsudo, 2-870-1,

Sakaecho-Nishi, Matsudo, Chiba 271-8587, Japan.

Tel: +81-47-360-9332, Fax: +81-47-360-9328,

E-mail address: abiko.yoshimitsu@ nihon-u.ac.jp the synovial tissue and synovial fluid of joints, ultimately leading to destruction of cartilage and bone. ${ }^{2)}$ Inflammation of the synovial lining of joints results in further increase in the expression of inflammatory cytokines and chemokine-mediated recruitment of additional inflammatory cells, as well as activation of $\mathrm{B}$ cells with autoantibody production. A vicious cycle of altered cytokine and signal transduction pathways and inhibition of programmed cell death contribute to cartilage and bone destruction by human fibroblast-like synoviocytes and osteoclasts. ${ }^{3-5)}$ Collagen-induced

Manuscript received: October 7th, 2010

Accepted for publication: November 12th, 2010 
arthritis (CIA) is an animal model of RA that is widely used to address questions regarding the pathogenesis of RA and to validate therapeutic targets. The pathological features of CIA rat also include the proliferative synovitis with infiltration of polymorphonuclear and mononuclear cells, pannus formation, cartilage degradation, and erosion of bone. ${ }^{6}$

Elevated levels of IL-1ß have been reported in the early phase of RA. ${ }^{7)}$ IL-1ß is known to up-regulate the expression of cell adhesion molecules on endothelial cells, thereby directing the emigration of blood cells from the circulation into the synovium. ${ }^{8,9)}$ It is well known that IL-1ß gene transcription is induced by IL$1 \beta$ as the autocrine system in rheumatoid synovial cells through AP-1 and NF-kappaB signaling. 10) Therapeutic options for RA by reducing the activities of IL-1 have been discussed, and recently, it becomes an important strategy to block the IL-1ß action for systemic inflammation. ${ }^{11)}$

Many treatments are available to relieve RA-associated pain. Non-steroidal anti-inflammatory drugs, disease-modifying anti-rheumatic drugs and newer biologics are currently used, but have side effects when used over a prolonged period and are not effective in all patients. A non-invasive physiological therapy such as low level light therapy (LLLT) could be important for and expected for managing pain, ${ }^{12)}$ and it has been used for many years for relief of the chronic pain in RA. ${ }^{13)}$ One of LLLT instruments, the linear polarized light instrument, Super Lizer ${ }^{\mathrm{TM}}$ (SL), noninvasive properties, has been developed. SL irradiation suppressed the superoxide anion and hypochlorite production of human neutrophils, and suggesting an inhibitory effect against chronic pain via the reduction of reactive oxygen species production and opsonic activity. ${ }^{14)}$ It has also been reported that RA-affected temporomandibular joint pain was reduced by SL irradiation. 15) Furthermore, SL was used in orthopedics and anesthesiology to treat arthralgia and neuralgia, and suggested SL is a useful tool for the treatment of alopecia areata. 16) More recently, Ide ${ }^{17)}$ reported that the significant analgesic effects of SL to RA patients by double blind test. However, the molecular mechanism of anti-inflammatory effect of LPIL to RA is unknown.

A novel human rheumatoid fibroblast-like synoviocyte line, MH7A, has been established by immortalization with SV40 $\mathrm{T}$ antigen and retains the morphological and functional characteristics of primary synovial cells, thus the cell was used often in RA research. 18) On the other hand, autoimmune type of CIA has been developed and widely used in the study RA, because its pathological features are similar to RA. ${ }^{19)}$
In the present study, we examined the effect of SL irradiation on the IL- $1 ß$ gene expression in the human RA synovial cell, MH7A. We also examined the usefulness of SL on the inflammation of CIA rat, and IL- $1 ß$ production in knee joints of CIA RA rat by immunohistochemisty.

\section{Materials and Methods}

\section{Synovial cell culture}

MH7A human synovial cells (Cell Bank, Riken Bioresource Center, Ibaraki, Japan) were cultured in RPMI 1640 medium (Gibco-BRL Life Technologies Inc., Rockville, MD) supplemented with $10 \%$ fetal calf serum (FCS) and penicillin-streptomycin at $37^{\circ} \mathrm{C}$ under a $5 \% \mathrm{CO} 2$ atmosphere. MH7A cells were treated with IL-1ß $(0.1 \mathrm{U} / \mathrm{ml})$ and irradiated by SL.

\section{Animal experiment}

Female Lewis (LEW/CrlCrlj) rats, 6 weeks old, were injected with type II collagen (Sigma, Tokyo, Japan) in $250 \mu \mathrm{l}$ of $0.1 \mathrm{M}$ acetic acid emulsified in an equal volume of complete Freund's adjuvant (Difco Labs, Michigan, USA) containing $2 \mathrm{mg} / \mathrm{ml}$ of muramyl dipeptide (Wako, Tokyo, Japan) by multiple intradermal injections. Rats were anaesthetized with an intraperitoneal injection of sodium pentobarbital (Somnopentyl ${ }^{\circledR}$, Kyoritsu Seiyaku, Tokyo, Japan) at 25 $\mathrm{mg} / \mathrm{kg}$ prior to the injection. All animals were maintained and used in accordance with the guide the Care and Use of Laboratory Animals of Nihon University, School of Dentistry at Matsudo (No. 04-008).

\section{SL irradiation}

A Super LizerTM (HA2200, Tokyo Iken Co., Ltd, Tokyo, Japan) was used to irradiate cells and rat knees. For irradiation to $\mathrm{MH7A}$, an output spectrum was at wavelengths ranging from $600 \mathrm{~nm}$ to $1600 \mathrm{~nm}$, pulsed irradiation at a frequency of $1 \mathrm{~Hz}$, which produced an energy density of $3.8 \mathrm{~J} / \mathrm{cm}^{2}$. For CIA rat, the irradiation time was $20 \mathrm{~min}$, which equaled an incident energy density of $7.64 \mathrm{~J} / \mathrm{cm}^{2}$. Each experimental group was carried out by 3 rats.

\section{DNA microarray analysis}

Total cellular RNA was isolated from MH7A using Trizol (GIBCO BRL, Life Technologies, Rockville, MD, USA) by a FastPrep machine (FP120; BIO 101), and cDNA was synthesized using a Superscript II RNaseH() reverse transcriptase system (Invitrogen) with oligo $\mathrm{d}(\mathrm{T}) 12-18$ primer at $42^{\circ} \mathrm{C}$ for 1 hour. Total RNA were 
then converted to cDNA by reverse transcription using T7-(dT) 24 primer (Amersham Biosciences, GE Healthcare, NJ) and reverse transcriptase (Invitrogen Co.). Biotinylated cRNA samples were amplified from cDNA by in vitro transcription with an Enzo

High Yield RNA Transcript Labeling System (Enzo Biochem, NY). The fragmented cRNA was then hybridized to a Human Genome Focus Array HG-8500 GeneChip (Affymetrix Inc.). The scanned images were analyzed using GeneSpring 4.0 software (Silicon Genetics, Redwood City, CA). We set a cut off of $>=1.5$-fold change for "induction" and "repression."

\section{RT-PCR and Real time PCR Analysis}

RT-PCR and real-time PCR reactions were carried out using a DNA thermal analyzer (RFN-Gene TM 6000; Corbett Life Science, Sidney, Australia). Amplification by PCR was started with an initial incubation at $95^{\circ} \mathrm{C}$ for 15 seconds to activate the Taq DNA polymerase, and then performed at $95^{\circ} \mathrm{C}$ for 5 seconds and $56^{\circ} \mathrm{C}$ for 15 seconds by adequate cycles. RT-PCR products were electrophoresed on 1.5\% agarose gel, followed by staining with ethidium bromide to examine the size of PCR products. Real-time PCR was carried out with SYBR Premix Ex Taq ${ }^{\text {TM }}$ (Perfect Real-Time PCR, Takara, Japan) and a Green PCR kit (Qiagen). To calculate gene expression fold changes, the initial template concentration was derived from the cycle number at which the fluorescent signal crossed the threshold in the exponential phase of the real-time PCR reaction. The mRNA copy unit was given by the cycle threshold value from the fluorescent signal of all the samples, including the standard curve and target genes, follow- ing the method provided by Corbett Life Science Company using RFN-Gene ${ }^{\mathrm{TM}} 6000$ software. Details were described in an operation manual, version 1.7.40, 2006. Each assay was normalized to GAPDH (glyceraldehyde-3-phosphate dehydrogenase) mRNA levels.

The DNA primer sequences were 5'-agctggaattgagtctgccc-3'(the forward primer for IL-1ß gene); 5'-cacaggactctctgggtacag-3'; (the reverse primer for IL$1 \AA$ gene), (predicted size $=164$ bp); 5'-atcaccatcttccaggag-3'(the forward primer for GAPDH); and 5'-atcgactgtggtcatgag-3'(the reverse primer for GAPDH gene), (predicted size $=318 \mathrm{bp}$ ). Values were calculated as means \pm standard deviation (SD). Comparisons were made between two groups using a Student's t-test.

\section{Immunobistochemistry}

Formalin-fixed, paraffin-embedded specimens were subjected to antigen retrieval and endogenous peroxidase blocking (30 min), and rinsed with phosphatebuffered saline (PBS). Immunostaining was performed using Elite ABC kits (Vector, Burlingame, CA, USA) and diaminobenzidine (Kirkegaard \& Perry, Gaithersburg, MD, USA) as a chromogen using anti-IL- $\beta$ polyclonal antibody (1:400; Sigma, Japan). Peroxidase-conjugated rabbit anti-mouse immunoglobulin diluted 1:10 in PBS supplemented with 2-vol\% heat-inactivated normal human serum was used. Peroxidase activity was visualised with $0.06 \%$ diaminobenzidine (Walter, Kiel, Germany) and 0.01 vol\% $\mathrm{H}_{2} \mathrm{O} 2$.

\section{Results}

Table1 shows the results of raw mRNA signals of DNA

Table 1. Raw signals of IL-1 related genes in MH7A shown in DNA microarray analysis.

\begin{tabular}{|c|c|c|c|c|c|c|}
\hline Gene & Genebank ID & Cont (Flag*) & IL-1ß (Flag*) & IL-1ß+SL (Flag*) & $\begin{array}{l}\text { IL1ß/Cont } \\
\left(\text { Fold }^{* *}\right)\end{array}$ & $\begin{array}{c}\text { IL-1ß+SL/ } \\
\text { IL-1ß }\left(\text { Fold }^{* *}\right)\end{array}$ \\
\hline IL1A & NM_000575 & $71.8(\mathrm{P})$ & $51.7(\mathrm{P})$ & $53.9(\mathrm{P})$ & 0.9 & 1.0 \\
\hline IL1B & NM_000576 & $157.6(\mathrm{M})$ & $331.9(\mathrm{P})$ & $248.6(\mathrm{P})$ & 2.7 & 0.7 \\
\hline IL1R1 & NM_000877 & $241.9(\mathrm{P})$ & $188.7(\mathrm{P})$ & $207.5(P)$ & 1.0 & 1.0 \\
\hline IL1R2 & NM_004633 & $55.6(\mathrm{P})$ & $45.5(\mathrm{P})$ & $39.6(\mathrm{P})$ & 1.0 & 0.8 \\
\hline IL1RAPL1 & AF284435 & $168.6(\mathrm{P})$ & $129.7(\mathrm{P})$ & $133.0(\mathrm{P})$ & 1.0 & 1.0 \\
\hline IL1RAPL2 & NM_017416 & $24.2(\mathrm{~A})$ & $12.4(\mathrm{~A})$ & $10.4(\mathrm{~A})$ & - & - \\
\hline IL1RL1 & $\mathrm{AB} 012701$ & $5.5(\mathrm{~A})$ & $2.2(\mathrm{~A})$ & $2.7(\mathrm{~A})$ & - & - \\
\hline IL1RL2 & NM_003854 & $2.1(\mathrm{~A})$ & $2.3(\mathrm{~A})$ & $0.7(\mathrm{~A})$ & - & - \\
\hline IL1RN & U65590 & $2.9(\mathrm{~A})$ & $9.0(\mathrm{~A})$ & $11.0(\mathrm{~A})$ & - & - \\
\hline
\end{tabular}

* Flag (P), Marginal (M) or (A) indicate the reliability of the data according to present $(\mathrm{P})$ or absent $(\mathrm{A})$ of gene expression in GeneChip.

** Fold, fold change by normalization against the median of the corresponding to control. IL1A(interleukin 1 alpha), IL1B (interleukin 1 beta) IL1R (interleukin receptor), IL1RAP (interleukin 1 receptor associated protein), IL1RL (interleukin 1receptor-like protein), IL1RN (interleukin 1 receptor antagonist). 

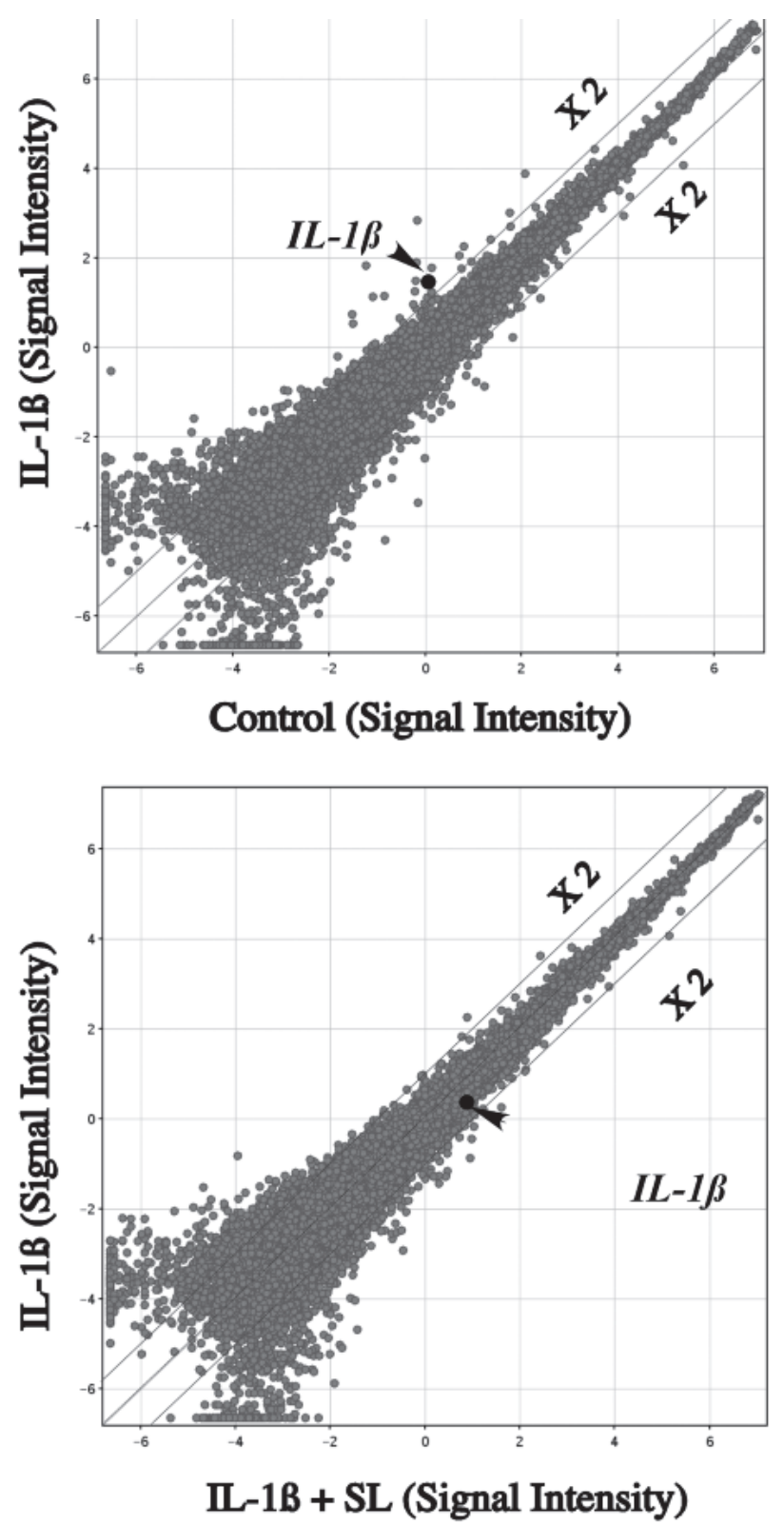

Fig. 1: A scatter plot of mRNA levels of IL-1ß.

microarray analysis of IL-1ß related gene families in MH7A cells with or without SL irradiation. The IL-1 related gene families expressed were selected by Flag analysis as "Present" (P) with more than 1.5-fold change. As a result, only IL-1ß was identified as significant by "Present" with more than 1.5-fold change, and other IL-1 related genes were "Absent" or less than 1.5fold change. Then, we focused on IL-1ß expression and studied further.

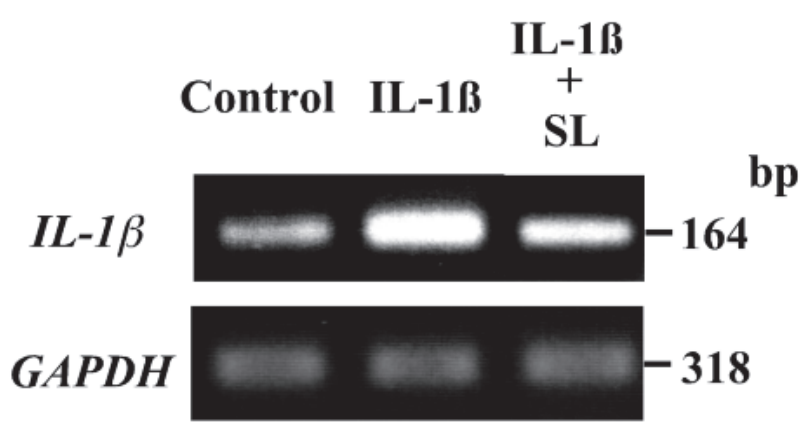

Fig. 2: 2 RT-PCR analysis of mRNA levels of IL-1ß. An ethidium bromide-staining pattern of the amplified PCR products using agarose gel electrophoresis.

A scatter plot of gene expression profile was shown in Fig. 1. IL-1ß mRNA level was increased in IL-ß3-challenged MH7A when compared to control, and SL significantly reduced IL- $\beta$-challenged IL- $\beta$ mRNA level as an autocrine manner.

To further investigate the elevated mRNA level of the IL-1ß gene, RT-PCR analysis was performed. As shown in Fig. 2, RT-PCR-amplified DNA band of IL-1ß in IL- $ß-$ challenged MH7A cells was higher in density than that in control, and SL reduced the density of IL-1ß DNA band in all these samples. In contrast, mRNA levels of GAPDH, the housekeeping control, showed no differences in all these samples.

Another experiment to determine the exact rates of enhancement of IL-1ß gene expression was performed using real-time PCR. The results in real-time PCR were converted to mRNA and calculated as the copy units. As shown in Fig. 3, IL-1ß gene expression was increased by IL- 3 -challenge in MH7A, and it was significantly decreased by SL.

In CIA rat in vivo experiment, as shown in Fig. 4, CIA rat knee joints significantly shows the swelling, and SL irradiation reduced the swelling at 2-week.

Finally, phenotypic expression of IL-6 was examined by immunohistochemistry using anti- IL- $1 ß$ monoclonal antibody. Significant positive IL-1ß staining was found in CIA rat when compared to control, whereas the weak staining was observed in the CIA+SL group when compared to CIA group, suggesting that SL reduced IL$1 乃$ production, as shown in Fig. 5 . 


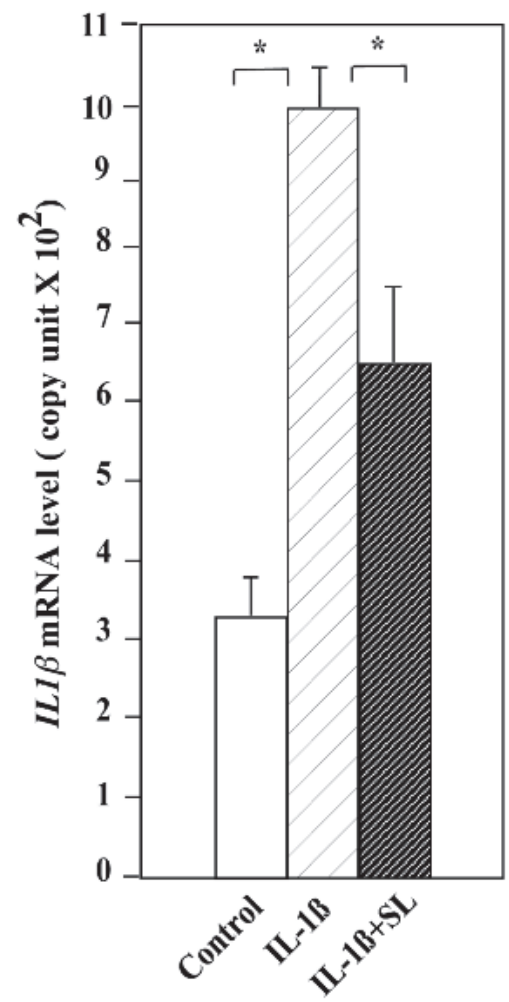

Fig. 3: 3 Real-time PCR analysis of IL-1ß mRNA levels. Results were expressed as mRNA copy unit by normalization to a housekeeping gene (GAPDH). Significant differences were determined using Student's $t$-test. ${ }^{*} p<0.01 \mathrm{n}=3$.

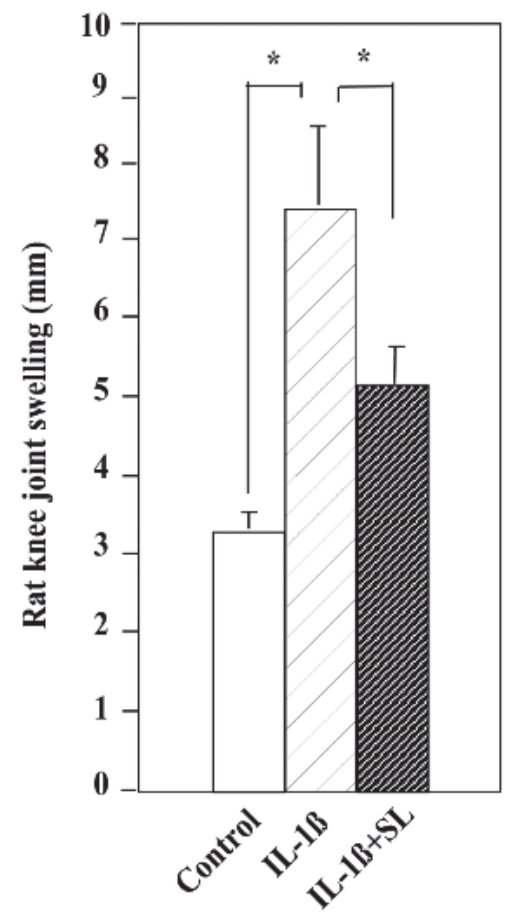

Fig. 4: Effect of SL on the swelling of CIA rats.

* $p<0.01 \mathrm{n}=4$.

\section{Control}

CIA

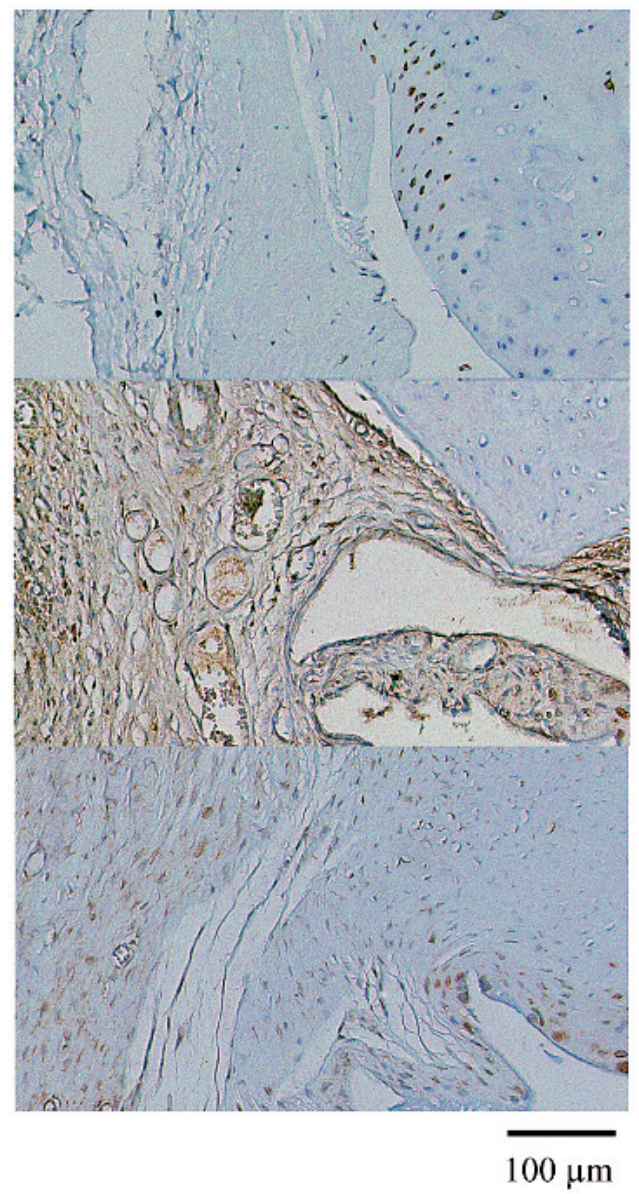

Fig. 5: Immunostaining of IL-1ß. Representative photomicrographs of sections of rat knee joints, with antibody against IL-1ß. 


\section{Discussion}

To our knowledge, only one report has been published concerning the effect of LLLT on the reduction of IL-1ß production. Yamaura et al ${ }^{20)}$ treated the fibroblast-like synoviocytes with 810nm LLLT, and analyzed IL-1ß gene expression using RT-PCR, and protein levels by ELISA. As results, IL-1ß production was shown to be decreased both mRNA and protein. So far, there is no report on the effect of SL on IL-1ß gene expression and production. In the present study, we demonstrated that SL decreased IL-1ß gene expression in MH7A. Furthermore, SL reduced the swelling of CIA rat knee in vivo, and we confirmed the reduction of IL$1 ß$ production in CIA knee joints by immunohistochemistry.

Intra-articular injection of IL-1ß into rabbit knee joints was reported to induce the accumulation of polymorphonuclear and mononuclear leukocytes in the joint space. ${ }^{21)} \mathrm{IL}-1 \beta$ is present in the synovial lining layer and in focal areas of the inflamed synovium

\section{References}

1: Pincus T (1995): Long-term outcomes in rheumatoid arthritis. Br J Rheumatol, 34:59-73.

2: Gay S, Gay RE, Koopman WJ (1993): Molecular and cellular mechanisms of joint destruction in rheumatoid arthritis: two cellular mechanisms explain joint destruction? Ann Rheum Dis, 52: 3947.

3: Dayer JM (2002): The saga of the discovery of IL-1 and TNF and their specific inhibitors in the pathogenesis and treatment of rheumatoid arthritis. $J$ Bone Spine 69: 123-132.

4: Inoue H, Takamori M, Nagata N, Nishikawa T, Oda H, Yamamoto S, Koshihara Y (2001): An investigation of cell proliferation and soluble mediators induced by interleukin $1 \beta$ in human synovial fibroblasts: comparative response in osteoarthritis and rheumatoid arthritis. Inflamm Res, 50: 65-72.

5: Firestein GS (2005): Immunologic mechanisms in the pathogenesis of rheumatoid arthritis. J Clin Rheumatol, 11: S39-S44.

6: Trentham DE: Collagen arthritis in rats, arthritogenic lymphokines and other aspects. Int Rev Immunol, 4: 25-33 1988

7: Eastgate JA, Symons JA, Wood NC, Grinlinton FM, di Giovine FS, Duff GW (1988): Correlation of plasma interleukin 1 levels with disease activity in rheumatoid arthritis. Lancet, 2: 706-709.

8: Abbot SE, Kaul A, Stevens CR, Blake DR (1992): of mice with antigen-induced arthritis. ${ }^{22)}$ Furthermore, a single injection of anti-IL-1ß antibodies resulted in reduced joint swelling by and proteoglycan breakdown. ${ }^{23)}$

TNF- $\alpha$ was first shown to be an inflammatory molecule causing fever and to induce IL-1 production. 24) Subsequently, neutralization of TNF- $\alpha$ by antibodies was reported to reduce spontaneous production of IL-1 from synovial explants in cultures. ${ }^{25)}$ These reports suggest the importance of IL-1 as the downstream mediator of TNF-induced disease. Blocking a downstream cytokine such as IL-1 directly targets many pathological processes, while avoiding widespread impairment of host defense mechanisms; these results imply that the reduction of IL-1ß production will be useful approach to RA therapy. Thus, SL may reduce inflammation in RA, thereby alleviating joint pain, by reducing the level of inflammatory cytokine IL-1ß. This mechanism may be more general and underlie the beneficial effects of SL on inflammatory conditions in RA

Isolation and culture of synovial microvascular endothelial cells. Characterization and assessment of adhesion molecule expression. Arthritis Rheum, 35:401-406.

9: Proudman SM, Cleland LG, Mayrhofer G (1999): Effects of tumor necrosis factor- $\alpha$, interleukin-1ß, and activated peripheral blood mononuclear cells on the expression of adhesion molecules and recruitment of leukocytes in rheumatoid synovial xenografts in SCID mice. J Rheumatol, 26:18771889.

10: Abe M, Tanaka Y, Saito K, Shirakawa F, Koyama Y, Goto S, Eto S (1997): Regulation of interleukin (IL)-1beta gene transcription induced by IL-1beta in rheumatoid synovial fibroblast-like cells, E11, transformed with simian virus 40 large $\mathrm{T}$ antigen. $J$ Rheumatol, 24:420-429.

11: Dinarello CA (2004): Therapeutic strategies to reduce IL-1 activity in treating local and systemic inflammation. Curr Opin Pharmacol, 4:378-385.

12: Mester E, Mester AF, Mester A (1985):The biomedical effects of laser application. Lasers Surg Med, 5: 31-39.

13: Brosseau L, Welch V, Wells G, Tugwell P, de Bie R, Gam A, Harman K, Shea B, Morin M (2000): Low level laser therapy for osteoarthritis and rheumatoid arthritis: a metaanalysis. J Rheumatol. 27:1961-1969. 
14: Shiraishi M, Suzuki K, Nakaji S, Sugawara K, Sugita N, Suzuki KJ, Ohta S (1999): Effect of linear polarized near-infrared ray irradiation on the chemiluminescence of human neutrophils and serum opsonic activity. Luminescence, 14:239-243.

15: Yokoyama K, Oku T (1999): Rheumatoid arthritisaffected temporomandibular joint pain analgesia by linear polarized near infrared irradiation. Can J Anaesth, 46: 683-687.

16: Yamazaki M, Miura Y, Tsuboi R, Ogawa H (2003): Linear polarized infrared irradiation using Super Lizer is an effective treatment for multiple-type alopecia areata. Int J Dermatol, 42:738-740.

17: Ide (2009): Phototherapy for chronic pain treatment. Masui, 58:1401-1406.

18: K. Miyazawa, A. Mori, H. Okudaira (1998): Establishment and characterization of a novel human rheumatoid fibroblast-like synoviocyte line, MH7A, immortalized with SV40 T antigen. J Biochem, 124: 1153-1162.

19: Trentham DE, Townes AS, Kang AH (1977): Autoimmunity to type II collagen an experimental model of arthritis. J Exp Med, 146: 857-868.

20: Yamaura M, Yao M, Yaroslavsky I, Cohen R, Smotrich M, Kochevar IE (2009): Low level light effects on inflammatory cytokine production by rheumatoid arthritis synoviocytes.Laser Surg Med, 41: 282-290

21: Henderson B, Pettipher ER (1989): Arthritogenic actions of recombinant IL-1 and tumour necrosis factor alpha in the rabbit: Evidence for synergistic interactions between cytokines in vivo. Clin Exp Immunol, 75: 306-310.

22: van de Loo AA, Arntz OJ, Bakker AC, van Lent PL, Jacobs MJ, van den Berg WB (1995): Role of interleukin 1 in antigen-induced exacerbations of murine arthritis. Am J Pathol, 146: 239-249.

23: Van Lent PL, Van De Loo FA, Holthuysen AE, Van Den Bersselaar LA, Vermeer H, Van Den Berg WB (1995): Major role for interleukin 1 but not for tumor necrosis factor in early cartilage damage in immune complex arthritis in mice. J Rheumatol, 22: 2250-2258.

24: Dinarello CA, Cannon JG, Wolff SM, Bernheim HA, Beutler B, Cerami A, Figari IS (1986): Tumor necrosis factor (cachectin) is an endogenous pyrogen and induce production of interleukin 1. J Exp Med, 163:1433-1450.

25: Brennan FM, Chantry D, Jackson A, Maini R, Feldmann M (1989): Inhibitory effect of TNF alpha antibodies on synovial cell interleukin- 1 production in rheumatoid arthritis. Lancet 8657:244-247.

\section{Acknowledgement}

Supported in part by the "Academic Frontier" Project for Private Universities: a matching fund subsidy from Ministry of Education, Culture, Sports, Science and Technology, 2007-2011, and by Grant-in-Aid for Scientific Research from Japan Society for the Promotion of Science (B21390497). We thank Tokyo Iken Co Ltd, for excellent technical assistance of Ms Asayo Imaoka and providing Super Lizer TM. 